\title{
Correction to: Comment on "Urinary incontinence during pregnancy: prevalence, experience of bother, beliefs, and help-seeking behavior"
}

\author{
Serveh Parang ${ }^{1,2} \cdot$ Kamyar Mansori $^{3}$
}

Published online: 29 January 2022

(c) The International Urogynecological Association 2022

\section{Correction to: Int Urogynecol J (2021) 32:3101-3101 \\ https://doi.org/10.1007/s00192-021-04974-w}

In the original version of this article, affiliation details of author Kamyar Mansori was inadvertently removed during production. Please see below the correct affiliations of both authors:

1 Clinical Care Research Center, Research Institute for Health Development, Kurdistan University of Medical Sciences, Sanandaj, Iran

2 Faculty of Nursing and Midwifery, Kurdistan University of Medical Sciences, Sanandaj, Iran

3 Department of Biostatistics and Epidemiology, School of Medicine, Zanjan University of Medical Sciences, Zanjan, Iran

The original article has been corrected.

Publisher's note Springer Nature remains neutral with regard to jurisdictional claims in published maps and institutional affiliations.

The original article can be found online at https://doi.org/10.1007/ s00192-021-04974-w.

Kamyar Mansori

kamyarmansori@yahoo.com

1 Clinical Care Research Center, Research Institute for Health Development, Kurdistan University of Medical Sciences, Sanandaj, Iran

2 Faculty of Nursing and Midwifery, Kurdistan University of Medical Sciences, Sanandaj, Iran

3 Department of Biostatistics and Epidemiology, School of Medicine, Zanjan University of Medical Sciences, Zanjan, Iran 